\title{
XXIX. An account of two children born with cataracts in their eyes, to show that their sight was obscured in very different degrees; with experiments to determine the proportional knowledge of objects acquired by them immediately after the cataracts were removed
}

\section{Everard Home Esq. F. R. S.}

To cite this article: Everard Home Esq. F. R. S. (1807) XXIX. An account of two children born with cataracts in their eyes, to show that their sight was obscured in very different degrees; with experiments to determine the proportional knowledge of objects acquired by them immediately after the cataracts were removed, Philosophical Magazine Series 1, 28:111, 203-210, DOI: $10.1080 / 14786440708563507$

To link to this article: http://dx.doi.org/10.1080/14786440708563507

Published online: 18 May 2009.

Submit your article to this journal $\sqsubset$

山 Article views: 3 
netrated the pores of the bronze and preserved it from rust. Naturalists will soon see if this reasoning, which seems satisfactory to Plutarch and his contemporaries, can be admitted at present.

The time of Alexander was the epoch at which the art of founding flourished most in Greece. The Athenians erected to Demetrius Phalereus, who governed Athens for ten years, 36u bronze statues, several of which were equestran, or accompanied with chariots and horses; and, what appears almost incredible, all these works were commenced and finished in the space of 300 days*. Lysippus. seems to have exhausted this art, for it fell with him.

[To be continued.]

XXIX. An Account of two Children lorn with Cataracts in their Eyes, to show that their Sight was obscured in very different Degrces; with Experiments to determine the proportional Knowledge of Oljects acquired by them immediately after the Cataracts were removed. By Everand Hume, Esq. F. R.S.

$M_{\text {R. Cheselden's observations on this subject, recorded }}$ in the Phil. Trans. for the year 1728, printed out two matcria. Sucts; that vision alone gives no idea of the figure of oujects, or their distance froris the eve, since a very intelligent boy, 13 years of age, upon recuvsring his sight was unalie to distinguish the outline of any thing placed before him, and thonght that every object touched his eve.

Mr. Ware's cases, which have also a place in the Phil. Trans. for 1801, and are compared with that of Mr. Cheselden, appear to lead to a different conclusion. The following observations are laid before the society with a view to explain this circumstance.

\section{Case I.}

William Stiff, twelve years of age, was admitted into St. George's Hospital, under my care, on the 17 th of July 1806, with cataracts in his eyes, which, according to the 
account of his mother, existed at the time of birth. From earliest infancy he never stretched out his hand to catch at any thing, nor were his eyes directed to objects placed before him, but rolled about in a very unusual manner, although in other respects he was a lively child. The eyes were not examined till he was six months old, and at that time the cataracts were as distinct as when he was received into the hospital.

Previous to an operation being performed, the following circumstances were ascertained respecting his vision. He could distinguish light from darkncss, and the light of the sun from that of fire or candles : he said it was redder, and more pleasant to look at, but lightning made a still stronger impression on his eyes. All these different lights he called red. The sun appeared to him the size of his hat. The candle flame was larger than his finger, and smaller than his arm. When he looked at the sun he said it appeared to touch his eye. When a lighted candle was placed before him both his eyes were directed towards it, and moved together. When it was at any nearer distance than 12 inches, he said it touched his eyes. When moved further off he said it did not touch them ; and at 22 inches it became invisible.

On the 21st of July the operation of extracting the crystalline lens was performed on the left eye. The capsule of the lens was so very strong as to require some force to penetrate it. When wounded, the contents, which were fuid, rushed out with great violence. Light became very distressing to his eye, and gave him pain. After allowing the eye-lids to remain closed for a few minutes, and then opening them, the pupil appeared clear, but he could not bear exposure to light. On my asking him what he had seen, he said, "Your head, which seemed to touch my eye:" but he could not tell its shape. He went to bed, and took an opiate draught : the pain in his eye lasted about an hour, after which he fell asleep. The whole of that day the light was distressing to his eye, so that he could not bear the least exposure to it.

On the $22 \mathrm{~d}$ the eye-lids were opened to examine the eye. 
The light was less offensive. He said he saw my head, which touched his eye. There was so much inflammation on the eye-ball, that a lecch was applied to the temple, and the common means for removing inflammation were used.

On the $23 d$ the eye was less inflamed, and he could bear a weak light. The pupil was of an irregular figure, and the wounded cornea had not united with a smooth surface. $\mathrm{He}$ said he could see several gentlemen round him, but could not describe their figure. My face, while I was looking at his eye, he said was round and red.

On the 25th the inflammation had subsided, but on the 27 th returned, and continued, notwithstanding different means were employed for its removal, till the ist of August, when it was almost entirely gone. On the 4 th the eye was apparently so well that an attempt was made in the presence of Mr. Cavendish and Dr. Wollaston to ascertain its powers of vision; but it was so weak that it became necessary to shade the glare of light by hanging a white cloth before the window. The least exertion fatigued the eye, and the cicatrix on the cornea, to wlich the iris had become attached, drew it down so as considerahly to diminish the pupil. From these circumstances nothing could be satisfactorily made out respecting the boy's vision. On the 11 th a second attempt was made in the presence of Mr. Cavendish, but the pupil continued so contracted and irregular, and the eye so imperfect in its powers, that it became necessary a second time to postpone any experiments.

On the 16th of September the right eye was couched. This operation was preferred after what had happened to the other eye, in the hope that there would not be the same degree of inflammation, and as the former cataract was fluid, there was every reason to believe that couching would in this instance be most, efficacious.

The operation gave pain, and the light was so distressing to his eye that the lids were closed as soon as it was over, and he was put to bed. The consequent inflammation was not severe; but as soon as the fluid cataract, which had been diffused through the aqueous humour was absorbed, the cap- 
sule of the lens was found to be opaque, and the sight consequently imperfect. The eyes were not examined with respect to their vision till the 13 th of October, during which period the boy remained quiet in the hospital. On that day the upper part of the pupil of the left eye had in some measure recovered its natural state, and had become transparent, but the cicatrix in the cornea was more extensively opaque than before. The light now was not distressing to either eye, and when strong, he could readily discern a white, red, or yellow colour, particularly when bright and shining. The sun and other objects did not now seem to touch his eyes as before, they appeared to be at a short distance from him. The eye which had been couched had the most distinct vision of the two, but in both it was im.perfect. The distance at which he saw best was five inches.

When the object was of a bright colour, and illuminated by a strong light, he could make out that it was flat and broad; and when one corner of a square substance was pointed out to him, he saw it, and could find out the other, which was at the end of the same side, but could not do this under less favourable circumstances. When the four corners of a white card were pointed out, and he had examined them, he seemed to know them : but when the opposite surface of the same card, which was yellow, was placed before him, he could not tell whether it had corners or not, so that he had not acquired any correct knowledge of them, since he could not apply it to the next coloured surface, whose form was exactly the same, with that, the outline of which the eye had just been taught to trace.

Case II.

John Salter, seven years of age, was admitted into St، George's Hospital on the 1st of October, 1806, under my care, with cataracts in both eyes, which according to the accounts of his relations had existed from his birth.

After he was received into the hospital, the following circumstances were ascertained respecting his vision. The pupils contracted considerably when a lighted candle was 
placed before him, and dilated as soon as it was withdrawn. He was capable of distinguishing colours with tolerable accuracy, particularly the more bright and vivid ones.

On the 6 th of October the left eye was couched. This operation was preferred to extraction, from a belief that the cataracts were not solid, and as the injury done to the capsule by the operation would be less, there was not the same chance of inflammation, the disposition for which had been so strong in the former case. As the eye was not irritable, and was likely to be but little disturbed by this operation, every thing was previously got ready for ascertaining his knowledge of objects, as soon as the operation was over, should the circumstances prove favourable. The operation was attended with success, and gave very little pain. The eye was allowed ten minutes to recover itself : a round piece of card of a yellow colour, one inch in diameter, was then placed about six inches from it. He said immediately that it was yellow, and on being asked its shape, said, "Let me touch it, and I will tell you." Being told that he must not touch it, after looking for some time, he said it was round. A square blue card, nearly the same size, being put before him, he said it was blue and round. A triangular piece he also called round. The different colours of the objects placed before him he instantly decided on with great correctness, but had no idea of their form. He moved his eye to different distances, and seemed to see best at 6 or 7 inches. His focal distance has been since ascertained to be 7 inches. He was asked whether the object seemed to touch his eye, he said "No;" but when desired to say at what distance it was, he could not tell. These experiments were made in the theatre of the hospital, in which the operation was performed, before the surgeons and all the students. He was highly delighted with the pleasure of sceing, and said it was "so pretty," even when no object was before him, only the light upon his eye. The eye was covered, and he was put to bed, and told to keep himself quiet; but upon the housesurgeon going to him half an hour afterwards, his eye w'as found uncovered, and he was looking at his bed curtains, which were close drawn. The bandage was replaced, but so delighted 
delighted was the boy with seeing, that he again immeriately removed it. This circumstance distressed the housesurgenn, who had been directed to prevent him from looking at any thing till the next day, when the experiment was to be repeated. Finding that he could not enforce bis instructions, he thought it most arlviseable to repeat the experiment about two hours after the operation. At first the boy called the different cards round; but upon being shown a square, and asked if he could find any corners to it, he was very desirous of touching it. This being refused, he examined it for some time, and said at last that he had found a corner, and then readily counted the four corners of the square; and afterwards when a triangle was shown him, he counted the comers in the same way; but in doing so his eye went along the edge from corner to corner, naming them as he went along.

Next day, when I saw him, be told me he had seen " the soldiers with their fifes and pretty things." The guards in the morning had marched past the hospital with their band; on hearing the music he had got out of bed, and gone to the window to look at them. Seeing the bright barrels of the musquets, he must in his mind have connected them with the sounds which he heard, and mistaken them for musical instruments. On examining the eye 24 hours after the operation, the pupil was found to be clear. A pair of scissors was shown him, and he said it was a knife. On being told he was wrong, he could not make them out; but the moment he touched them he said they were scissors, and seemed delighted with the discovery. On being shown a guinea at the distance of 15 inches from his eye, he said it was a seren shilling piece, but placing it about 5 inches from his eye, he knew it to be a guinea ; and made the same mistake, as often as the experiment was repeated.

From this time he was consequently improving himself by looking at, and examining with his hands, every thing within his reach, but he frequently forgot what he had learnt. On the 10th I saw him again, and I told him his eye was so well that he might go about as he pleased without leaving the room. He immediately went to the window, and called 
out, "What is that moving ?" I asked him what he thought it was? He said, "A dog drawing a whcelbarrow. There is one, two, three dogs drawing another. How very pretty !" These proved to be carts and horses on the road, which he saw from a two pair of stairs window.

On the $19 t h$, the different coloured pieces of card were separately placed before his eye, and so little had he gained in thirteen days, that he could not without counting their corners one by one tell their shape. This he dil with great facility, running his eye quickly along the outline, so that it was evident he was still learning, just as a child learns to read. He had got so far as to know the angles, when they were placed before him, and to count the number belonging to any one object.

The reason of his making so slow a progress was, that these figures had never been subjected to examination by touch, and were unlike any thing he was accustomed to see.

He had gat so much the habit of assisting his eyes with his hands, that nothing but holding them could keep them from the object.

On the 26 th the experiments were again repeated on the couched eye, to ascertain the degree of improvement which had been made. It was now found that the boy, on looking at any one of the cards in a good light, could tell the form nearly as readily as the colour.

From these two cases the following onnclusions may be drawn :

That, where the eye before the cataract is removed, has only been capable of discerning light, without being able to distinguish colours, objects after its removal will secm to touch the eye, and there will be no knowledge of their outline; which confirms the observations made by $\mathrm{Mr}$. Cheselden :

That where the eye has previously distinguished colours, there must also be an imperfect knowledge of distances, but not of outline, which however will afterwards be very soon acquired, as happened in Mr. Ware's cases. This is proved by the history of the first boy in the present paper, who before the operation, had no knowledge of colours or distances,

Vol, 28. No. 111. Aug. 1807. O but 
but after it, when his eye had only arrived a: the sarrie state, that the second boy's was iu before the oferation, he had learnt that the objects were at a distance, and of different coiours: that when a child has acquired a new sense, nothing but great pain or absolute coercion will prevent him frorh making use of it.

In a practical view, these cases confirm every thing, that has been stated by Mr. Pott and Mr. Ware, in proof of cataracts in children being generally soft, and in favour of couching, as being the operation best alapted for removing them. They also lead us to a conclusion of no small importance, which has not before been adrerted to ; that when the cataract has assumed a fluid form, the capsule, which is naturally a thin transparent membrane, has to resist the pressure of this fluid, which like every other discased accumulation is liable to increase, and distend it, and therefore the capsule is rendered thicker and more opaque in its substance, like the coats of encysted tumours in gineral.

As such a change is liable to take place, the earlier the operation is performed in all children, who have cataracts completely formed, the greater is their chance of having distinct vision after the operation. It is umnecessary to point out the advantages to be derived from its being done at a more early age, independent of those respecting the operation itself.

XXX. On the Decomposition of Light into its most simple Elements, leing Part of a Work upon Colours. By C. A. Prieun, late a Colonel in the Corps of Engineers.

[Continued from p. 170.]

First I considered, that boih the nature and quantity of the red, green, and violet mys, which I suppose to be the sole elements of white hight, are absolutely unknown. But I could likewise conceive them transformed into coloured matters of such intensity, or condensation, that the mix ture of an equal quantity of each should produce exactly white. 